\title{
Study on Hygiene Practice of the Adult Domestic Household Women Worker in Urban Slum Area of Dhaka City
}

\author{
A K M Majbah Uddin' \\ Md Monoarul Haque ${ }^{2+}$ \\ Yasin Arafat $^{3}$ \\ Suman Kumar Roy \\ Md Zahid Hasan Khan ${ }^{4}$ \\ Khaleda Islam ${ }^{5}$
}

'Department of Public Health \& Life Science University of South Asia, Dhaka, Bangladesh.

${ }^{2}$ Department of Community Nutrition Faculty of Public Health

Bangladesh University of Health Sciences (BUHS) Dhaka, Bangladesh.

${ }^{3}$ Department of Biochemistry and Cell Biology Bangladesh University of Health Sciences (BUHS) Dhaka, Bangladesh.

${ }^{4}$ Community Medical Institute

Gaibandha, Bangladesh

${ }^{5}$ Institute of Nutrition \& Food Science University of Dhaka, Dhaka, Bangladesh.

\section{*Correspondence to:}

\section{Md Monoarul Haque}

Fellow

Department of Community Nutrition

Faculty of Public Health

Bangladesh University of Health Sciences (BUHS)

125/1, Darus Salam, Mirpur, Dhaka-1216

Bangladesh.

Mobile : +88 01915839550

E-mail: monoarmunna@yahoo.com

http://www.banglajol.info/index.php/CMOSHMC

\begin{abstract}
Background: Globally, slums have been recognized as neglected communities with limited access to services. They are often characterized by deteriorated or poorly structured houses crowded together, poor environmental managements such as deficient access to safe drinking water and sanitation, stagnation of water, and poor drainage with excessive open sewers, excessive amount of uncollected rubbish, severe overcrowding, flies, and poor lighting. Objective: The purpose of this study was to explore hygiene practice of the adult domestic household women worker in urban slum area of Dhaka city. Methods: This cross sectional study was conducted among adult female domestic household workers ages between 19 to 45 years of the south Monipur slum of Dhaka city. The study was conducted from April 2012 to June 2012. About 95 samples were selected purposively to conduct this study. Results: The mean age of the respondent was 29.32 years. It also found that majority of the respondent $(87.37 \%)$ were married, $10.53 \%$ were separated and $2.11 \%$ were divorced. The mean income of the respondent was $2132.63 \mathrm{TK}$. Result found that $76.84 \%$ of the respondent use sandal in toilet and $23.16 \%$ of the respondent do not use sandal in toilet. It also showed that $69.47 \%$ of the respondent use soap everyday in bath and $30.53 \%$ of the respondent did not use soap everyday in bath. About $90.53 \%$ of the respondent brushing teeth everyday and $9.47 \%$ of the respondent did not brush teeth everyday. In addition to this $33.68 \%$ of the respondent cut nail regularly and $66.32 \%$ of the respondent did not cut nail regularly. Besides $85.26 \%$ of the respondent used soap to wash their hand after toilet, $2.11 \%$ used ash and $12.63 \%$ of the respondent used soil to wash their hand after toilet. Conclusion: The hygiene practice of adult domestic household workers is quite good but the overall practice condition is not in satisfactory state. Further in depth studies are needed to evaluate the actual scenario of the hygiene practice among adult domestic household workers.
\end{abstract}

Key words: Hygienic Status; Adult household; Urban Slum.

\section{INTRODUCTION}

The urbanization of different parts of the world constitutes a major demographic issue of the twenty- rst century. This is especially true for Bangladesh also. The unprecedented growth in the urban population in Bangladesh has also resulted in a large section of the population living in abject poverty in overcrowded slums ${ }^{1}$. Bangladesh is one of the most densely populated countries in the world, with more than 1000 people per sq $\mathrm{km}$. One quarter of the population lives in urban areas, where population density is 200 times greater than the national figure and population growth is twice the national average. By 2030, half the population (some 90 million people) will be living in urban areas, most of them below the poverty line ${ }^{2}$. Dhaka, the capital city of Bangladesh, is one of the fastest growing mega-cities in the world. Extreme poverty in rural areas is the main factor in driving the mass migration to urban centres. Yet, poverty is also the reality in urban areas, as a growing population places further strains on the limited infrastructure and services ${ }^{2,3}$. Globally, slums have been recognized as neglected communities with limited access to services. They are often characterized by deteriorated or poorly structured houses crowded together, poor environmental managements such as deficient access to safe drinking water and sanitation, stagnation of water, and poor drainage with excessive open sewers, excessive amount of uncollected rubbish, severe overcrowding, flies, and poor lighting ${ }^{4,5}$. 
These settings are compounded by inhabitation by migratory population living under stressful conditions. Millions of slumdwellers in Bangladesh live stressful lives among teaming rubbish because there is no waste disposal system. Slum houses perch on the edges of fetid cesspools as there is inadequate sewer drainage and little access to sanitary latrines. Raw sewage and industrial waste continue to be discharged into rivers and ponds. These unsanitary conditions are exacerbated by seasonal floods ${ }^{2}$. Slum residents live under the constant threat of eviction because their landlords lack official ownership of their shanties. In this context, people are not motivated to spend money on sanitation infrastructure. Poor sanitation leads to an increased prevalence of diarrhoea and other parasitic diseases ${ }^{6}$. People lives in urban slum in Dhaka city specially adult women those who are involved in domestic work have very limited access in hygiene practice, even we don't know their level of knowledge about hygiene practice. It is very important to explore their hygiene practice because they are vulnerable to spread disease to their family and to their work place also.

\section{MATERIALS AND METHODS}

\section{Study design}

This cross sectional study was conducted among adult female domestic household workers ages between 19 to 45 years of the south Monipur slum of Dhaka city. The study was conducted from April 2012 to June 2012.

\section{Sample size and sample method}

About 95 samples were selected purposively to conduct this study.

\section{Data analysis}

Data was collected through face to face interview by semistructured questionnaire. Collected data were coded and analyzed using SPSS-16 and plotted into different frequency table. Ethical issues are considered during collecting data and taken the informed consent from the respondents.

\section{RESULTS}

Table 1 showed that the percent distribution of the age of the respondent. It was found that the majority respondents $(45.26 \%)$ were in the age of $26-32$ years, $26.32 \%$ were in $19-25$ years, $28.42 \%$ were in $30-40$ years. The mean age of the respondent was 29.32 years. It also found that majority of the respondent $(87.37 \%)$ were married, $10.53 \%$ were separated and $2.11 \%$ were divorced. The above table showed that majority of the respondent $(48.42 \%)$ were illiterate but no schooling (only signature), $20.00 \%$ were illiterate and did not know signature and $31.58 \%$ were primary level (up to class 5). It was found that $19.95 \%$ respondent's monthly income was $<=1500 \mathrm{TK}$, $68.42 \%$ were 1501 to $2500 \mathrm{TK}$ and $12.63 \%$ respondent's monthly income was $>=2500 \mathrm{TK}$. The mean income of the respondent was $2132.63 \mathrm{TK}$. Result also found that $12.63 \%$ respondent's monthly total family income was $<=5000 \mathrm{TK}$, $42.11 \%$ were 5001 to $7000 \mathrm{TK}, 30.53 \%$ were $7001-9000 \mathrm{TK}$ and $14.74 \%$ respondent's monthly total family income was $>=9000 \mathrm{TK}$. The mean income of the respondent's total family was $7301.05 \mathrm{TK}$. Table 2 showed that $76.84 \%$ of the respondent use sandal in toilet and $23.16 \%$ of the respondent do not use sandal in toilet. It also showed that $69.47 \%$ of the respondent use soap everyday in bath and $30.53 \%$ of the respondent did not use soap everyday in bath. $90.53 \%$ of the respondent brushing teeth everyday and $9.47 \%$ of the respondent did not brush teeth everyday. In addition to this $33.68 \%$ of the respondent cut nail regularly and $66.32 \%$ of the respondent did not cut nail regularly. Besides $85.26 \%$ of the respondent used soap to wash their hand after toilet, $2.11 \%$ used ash and $12.63 \%$ of the respondent used soil to wash their hand after toilet. More than sixty percent of respondents had supply water which was showed in table 3 .

Table 1: Socio-demographic characteristics of the respondants $(n=95)$

\begin{tabular}{|c|c|c|}
\hline \multirow{2}{*}{$\begin{array}{l}\text { Variables } \\
\text { Age (in years) }\end{array}$} & \multirow[t]{2}{*}{ Frequency } & Percentage \\
\hline & & \\
\hline $19-25$ & 25 & 26.32 \\
\hline $31-40$ & 43 & 45.26 \\
\hline$>40$ & 27 & 28.42 \\
\hline Mean age & \multicolumn{2}{|c|}{$29.32 \pm 5.38$} \\
\hline \multicolumn{3}{|c|}{ Marital status } \\
\hline Married & & 87.37 \\
\hline Single & & 10.53 \\
\hline Divorced & & 2.11 \\
\hline \multicolumn{3}{|l|}{ Education: } \\
\hline Illiterate & & 20 \\
\hline Literate but $\mathrm{n}$ & nature) & 48.42 \\
\hline Primary & & 31.58 \\
\hline \multicolumn{3}{|c|}{ Monthly income (in Taka) } \\
\hline$<=1500$ & 18 & 18.95 \\
\hline $1501-2500$ & 65 & 68.42 \\
\hline 2500 & 12 & 12.63 \\
\hline Mean income & \multicolumn{2}{|c|}{$2132.63 \pm 608.35$} \\
\hline \multicolumn{3}{|c|}{ Monthly family income (in Taka) } \\
\hline$<=5000$ & 12 & 18.95 \\
\hline $5001-7000$ & 40 & 68.42 \\
\hline $7001-9000$ & 29 & 12.63 \\
\hline$>9000$ & 14 & \\
\hline Mean income & 7301.05 & \pm 1768.37 \\
\hline
\end{tabular}

Table 2: Hygiene practice of respondents $(n=95)$

Sandal use in toilet
Frequency Percentage

Use Sandal 73

76.84

Do not use sandal

22

23.16

Bath soap use everyday

Use Soap

66

69.47

Do not use Soap

29

30.53

Brushing teeth everyday

Brush Teeth Every day

86

Do nott brush Teeth Every day

9

Cut nail regularly

Regularly

Not Regularly

63

66.32

Hand wash after toilet

Soap

81

85.26

Ash

2.11

Soil

12.63 
Table 3: Source of drinking water $(n=95)$

\begin{tabular}{lcc} 
Source & Frequency & Percentage \\
Tube well & 32 & 33.68 \\
Supply water (WASA) & 63 & 66.32 \\
\hline
\end{tabular}

\section{DISCUSSION}

Study shows that majority (76.84\%) of the respondents use Sandal while using toilet. But till now $23.16 \%$ are not using sandal in toilet, which is a matter of concern. In case of using soap in bath every day, majority $(69.47 \%)$ of the respondents follow it but till now $30.53 \%$ don't practice it at all. About $90.53 \%$ respondents brush their teeth every day morning, which is good for their health and $85.26 \%$ respondents use soap to wash their hand after toilet. But majority of the respondents $(66.32 \%)$ do not cut their nail regularly. Although the above findings indicate the good condition of Hygiene practice in urban slum in Dhaka city but the overall condition is not in satisfactory level. The proportion of the population with access to improved sanitation in municipalities has risen from 53 percent in 1990 to 77 percent now. This level is higher now than that for metropolitan areas, where coverage has increased to only 75 percent from a level of 70 percent in $1990^{7,8,9}$. But till now sanitation coverage in urban slums is very low. Only $8.5 \%$ of households have access to improved sanitation facilities, compared with a national average of around $54 \%{ }^{10}$. Most slum dwellers have no option but to dispose in drains, open fields and river banks. The use of hanging latrines, suspended over ponds and rivers is twice as high in urban slums than the national average ${ }^{10}$. This means that urban water sources are more likely to be contaminated with raw sewage. Community latrines in slums are often dirty, badly maintained and lack privacy. Residents often have to wait in line to access them and this sometimes leads to heated exchanges. Common latrines also pose a security risk to women should they need to use them at night. In case of source of drinking water, majority $(66.32 \%)$ of the respondents depends on supply water where one third (33.68\%) have access of tube well. Which is really dangerous in condition. Access to clean water sources is a challenge in urban areas. According to the Joint Monitoring Programme of the World Health Organisation (WHO) and UNICEF, access to improved drinking water sources in urban areas of Bangladesh has declined from $88 \%$ in 1990 to $85 \%$ in $2008^{10}$. The situation is worse for slums but statistics on access is unclear. In a survey in 2009 about the living conditions of the urban poor in Bangladesh, $58 \%$ of all respondents reported water-sanitation-hygiene related diseases in their households during the three-month period preceding the survey ${ }^{11}$. In Dhaka, extensive pumping of groundwater has depleted some water sources, calling into question the sustainability of the city's groundwater supply. Surface water as a viable water source is also problematic as it is often polluted by untreated sewage and industrial waste.

\section{CONCLUSION AND RECOMMENDATION}

Although the findings of this study shows that the hygiene practice of adult domestic household workers is quite good but the overall practice condition is not in satisfactory state. Additionally the sample size is not representative to generalize the findings. Further in depth studies are needed to evaluate the actual scenario of the hygiene practice among adult domestic household workers.

\section{ACKNOWLEDGEMENT}

The authors express their sincere thanks to all the respondents of this study. No external funding was provided for this study.

\section{DISCLOSURE}

All the authors declared no competing interest.

\section{REFERENCES}

1. Sclar ED, Garau P, Carolini G. The 21st century health challenge of slums and cities. Lancet. 2005; 365: 901-903.

2. UNICEF, 2008, Sanitation, Hygiene and Water Supply in Urban Slums, cited: http://www.unicef.org/bangladesh/URBAN_Water_Sanitation_and_Hygiene.pdf, Accessed [5th April 2012].

3. Care Bangladesh, UNICEF and Government of Bangladesh Monitoring Survey Combined Report, 2005.

4. Harpham T. Health and the urban poor. Health Policy Plann. 1986; 1: 5-18.

5. Khan MH, Kraemer A. Socio-economic factors explain differences in public healthrelated variables among women in Bangladesh: a cross-sectional study. BMC Public Health. 2008; 8: 254.

6. Census of Slum Areas and Floating Population’, Bangladesh Bureau of Statistics, 1997.

7. Slums of Urban Bangladesh Mapping and Census 2005' published by the Centre of Urban Studies in May 2006 suggests that $35 \%$ of total population live in slum areas.

8. Khawaja M. Minnatullah, 2008, Achieving the Water and Sanitation MDGs in Bangladesh: Water and Sanitation Program for South Asia. The World Bank.

9. Multiple Indicator Cluster Survey (MICS), 2009.

10. UNICEF, 2011, Urban water challenges in Bangladesh, cited: http://www.unicef.org/bangladesh/Urban water_challenges_in_Bangladesh.pdf, Accessed: [5th March 2012].

11. Understanding Urban Inequalities in Bangladesh 2010 report. 